\title{
Editorials
}

\section{Confronting child obesity in primary care}

\section{SCALE OF THE PROBLEM}

Obesity as a risk for chronic disease has been called an 'unfolding crisis' in these pages $^{1}$ and a recent study identified a fourfold increase in children in England being admitted to hospital for obesity and related conditions in the past decade. ${ }^{2}$ We found that of these children three-quarters were not admitted for obesity itself, but for the management of related conditions including asthma, sleep apnoea, and type II diabetes. The number of bariatric surgery procedures rose dramatically in 10 years in children as young as 13 years old. Systematic review evidence suggests worsened cardiovascular risk profiles in overweight and obese children ${ }^{3}$ and together these findings raise the worrying prospect that we are seeing these diseases manifest themselves earlier in the life course. Currently one in three children in England are overweight, one in five are obese ${ }^{4}$ and every agency: government, the food industry, schools, the health profession and the family has been called to arms to tackle the problem. Charged with health care for $98 \%$ of the nation's 10 million children, we consider what role GPs and primary care providers can play.

\section{PARENTAL PERCEPTION AND MISSED OPPORTUNITIES IN PRIMARY CARE}

Recognition that a child is overweight or obese and that this can lead to health problems is the first step towards doing something about it, but this is a major stumbling block for childhood obesity. Researchers evaluating the UK National Child Measurement Programme Iwhere children are measured at primary and secondary school entryl found that $79 \%$ of parents of overweight children do not recognise this fact, and of those who do, $41 \%$ do not perceive it to be a health risk. ${ }^{5}$ Parents said the feedback on weight status did not cause offence but that they would prefer tailored advice and to discuss this with a trusted health professional before they would consider lifestyle change. ${ }^{6}$

Primary care practitioners are ideally placed to intervene in such cases and start a realistic and sensitive dialogue with children and their parents. But engaging parents and children to address weight problems in children can be a difficult task. Recent work in Bristol on the success of identifying obese children using primary

"Primary care practitioners are ideally placed ... to start a realistic and sensitive dialogue with parents who learn their child has a weight problem.

care records and inviting them for followup appointments found what some have considered disappointing results. Just under half $(47 \%)$ of those who were sent invitation letters went on to consult their GP and only $15 \%$ of the total discussed issues of weight at the resulting consultation. ${ }^{7}$ There is little systematic weight assessment of children in primary care, so such recognition by GPs relies on opportunistic efforts during health contacts initiated by parents for other conditions. But doctors regularly miss opportunities to discuss weight problems in around $40 \%$ of overweight patients. ${ }^{8}$ Yet adults can be encouraged to be more realistic about their weight and are more likely to modify diet and exercise when told by a physician that they are overweight in a straightforward but sensitive dialogue ${ }^{8}$ and so the same seems likely to be true of children.

Qualitative work with primary care practitioners has identified a number of possible reasons for this lack of engagement, including that a majority of them were unaware of National Institute for Health and Care Excellence (NICE) guidance on the management of childhood obesity. Behind this lack of awareness were a number of factors, from the familiar lack of time and competing demands, to a lack of faith in primary care as an appropriate setting. ${ }^{7}$ Other issues such as a concern for promoting a medical model of disease for an issue which is argued by many to be a social problem rather than the responsibility of the medical establishment were also raised.

Teenagers are among the hardest to reach yet form one of the most affected groups. Despite adolescence being a time of peak adult fitness their transition into a healthy adult life can be problematic. Engaging in risky behaviours, loss of family support if they leave home, and erratic contacts with health services renders them vulnerable to developing health problems. It is particularly notable that among the commonest reasons for hospital admission in obese teenage girls was for management of maternal and foetal complications. ${ }^{2}$ But perhaps recognition of an emerging weight problem in children and young people is itself too late given that patterns of dietary and sedentary behaviour have already become established. Education in pregnancy and advice for new families about diet and physical activity has not been fully researched yet, as a potential key intervention point in general practice.

\section{MAKING EVERY CONTACT COUNT}

As with many of the large scale issues facing the health service, notions of responsibility loom large. Responsibility is a theme which is heavily mentioned in Academy of Medical Royal Colleges Measuring Up, which cites the issue of obesity as the greatest public health crisis facing the UK. ${ }^{9}$ In recent years we have seen setbacks such as the decision to allow free schools to opt out of mandatory food- and nutrient-based standards, but also successes such as the recently announced traffic light system of nutritional labelling for foods sold in all of the major supermarkets. For healthcare professionals, Measuring Up recommends increasing training to allow the idea of 'making every contact count' to become a reality. This is noted to be particularly important for those healthcare professionals who have the greatest influence on patient behaviour, which seems
"Doctors regularly miss opportunities to discuss weight problems in around $40 \%$ of overweight patients. 
undoubtedly to be those in general practice. This is likely to be welcome in a workforce that finds it difficult to engage patients in discussion about weight issues. Research in this issue demonstrates that referral to a variety of weight loss programmes can be effective in adults, ${ }^{10}$ going some way to address a lack of tools and knowledge of what works in primary care. For children specifically, an electronic tool to estimate health risks and provide personalised weight management advice has been developed by the PROMISE (Paediatric Research in Obesity Multi-modal Intervention and Service Evaluation) programme (https://sites.google. com/site/promisenihr/).

Obesity is now endemic and the public has normalised its perception and acceptance of overweight status. Hence, management in secondary care has become an inappropriate and unsustainable solution. With the move of public health functions to local authorities there is little likelihood that a national public health strategy will emerge soon and NICE have recently consulted on managing overweight and obesity in children and young people. ${ }^{11}$ Primary care remains in the frame as the best component of the healthcare system in dealing with obesity, particularly in children. We must ensure we have adequate skills for intervention with children who have weight problems. Above all we must be brave enough to open up a two-way nonjudgemental dialogue when confronted with an overweight child.

\section{Sonia Saxena,}

Clinical Reader in Primary Care, Department of Primary Care and Public Health, Imperial College London.

\section{Anthony A Laverty,}

Research Assistant, Department of Primary Care and Public Health, Imperial College London.

\section{Provenance}

Commissioned; not externally peer reviewed.

\section{Competing interests}

The authors have declared no competing interests.

DOI: 10.3399/bjgp14X676285

\section{ADDRESS FOR CORRESPONDENCE}

\section{Sonia Saxena}

Department of Primary Care and Public Health, Imperial College London, 3rd Floor Reynolds Building, St Dunstan's Road, London W6 8RP, UK.

E-mail: s.saxenadimperial.ac.uk

\section{REFERENCES}

1. Yates T, Davies MJ, Khunti K. Obesity and chronic disease in younger people: an unfolding crisis. Br J Gen Pract 2012; 62(594): 4-5.

2. Jones Nielsen JD, Laverty AA, Millett C, et al. Rising obesity-related hospital admissions among children and young people in England: national time trends study. PLOS One 2013; 8(6): e65764.

3. Friedemann C, Heneghan C, Mahtani K, et al. Cardiovascular disease risk in healthy children and its association with body mass index: systematic review and meta-analysis. BMJ 2012; 345: e4759.

4. NHS Health and Social Care Information Centre, Lifestyles statistics. National child measurement programme: England, 2011/12 school year. https://catalogue.ic.nhs.uk/ publications/public-health/obesity/nati-chilmeas-prog-eng-2011-2012/nati-chil-measprog-eng-2011-2012-rep.pdf laccessed 10 Dec 2013).

5. Park MH, Falconer CL, Saxena S, et al. Perceptions of health risk among parents of overweight children: a cross-sectional study within a cohort. Prev Med 2013; 57(1): 55-59.

6. Falconer C, Park MH, Skow A, et al. Scoping the impact of the national child measurement programme feedback on the child obesity pathway: study protocol. BMC Public Health 2012; 12: 783. DOI:10.1186/1471-2458-12-783.

7. Banks J, Sharp DJ, Hunt LP, Shield JP. Evaluating the transferability of a hospitalbased childhood obesity clinic to primary care: a randomised controlled trial. Br J Gen Pract 2012; DOI: 10.3399/bjgp12X616319.

8. Post RE, Mainous AG 3rd, Gregorie SH, et al. The influence of physician acknowledgment of patients' weight status on patient perceptions of overweight and obesity in the united states. Arch Intern Med 2011; 171(4): 316-321. DOI: 10.1001/archinternmed.2010.549.

9. Academy of Medical Royal Colleges. Measuring Up: The Medical Profession's prescription for the nation's obesity crisis. http://www.aomrc.org.uk/publications/reportsa-guidance/doc_details/9673-measuring-up. html (accessed 2 Dec 2013).

10. Madigan CD, Daley A, Lewis A, et al. Which weight loss programmes are as effective as Weight Watchers ${ }^{\circledR}$ ? Noninferiority analysis. $\mathrm{Br}$ $J$ Gen Pract 2014: in press.

11. National Institute for Health and Care Excellence. Overweight and obese children and young people - lifestyle weight management services: guideline consultation. http:// guidance.nice.org.uk/PHG/75/Consultation/ Latest. (accessed 10 Dec 2013). 